\title{
Characterization of Malaysian velogenic NDV strain AF2240-I genomic sequence: a comparative study
}

\author{
Kavitha Murulitharan · Khatijah Yusoff • \\ Abdul Rahman Omar • Aidin Molouki
}

Received: 22 October 2012/ Accepted: 27 December 2012/Published online: 10 January 2013

(C) Springer Science+Business Media New York 2013

\begin{abstract}
Newcastle disease virus (NDV) strain AF2240 is a viscerotropic velogenic strain that is used as a vaccine challenge virus in Malaysia. The identification of the full length genome will be a crucial platform for further studies of this isolate. In this study, we fully sequenced the genome of a derivative of this strain named AF2240-I. The 15,192 nt long genome contains a 55-nt leader sequence at the $3^{\prime}$ whereas the trailer region consists of $114 \mathrm{nt}$ at the $5^{\prime}$. The intergenic sequences between the NP-P, P-M, M-F, F-HN, and HN-L genes comprise $1,1,1,31$, and $47 \mathrm{nt}$, respectively. The acknowledged cleavage site of fusion protein showed amino acid sequence of 112-R-R-Q-K-R-F-117, which corresponds to those of virulent NDV strains. Phylogenetic analysis of the whole virus genome shows that the strain AF2240-I belongs to genotype VIII and is more closely related to velogenic strains QH1, QH4, Fontana, Largo, and Italienas compared to other strains of NDV. Differences are noticed in the hemagglutinin-neuraminidase (HN) and matrix (M) gene between AF2240 and its derivative AF2240-I. This is the first report of a complete genome sequence of an NDV strain isolated in Malaysia.
\end{abstract}

Keywords Newcastle disease virus - Strain AF2240-I · Complete genome sequence

\section{Abbreviations \\ UTR Untranslated region}

K. Murulitharan · K. Yusoff · A. R. Omar · A. Molouki $(\bowtie)$ Institute of Biosciences, Universiti Putra Malaysia,

43400 Serdang, Selangor DE, Malaysia

e-mail: aidin_molouki@putra.upm.edu.my

K. Yusoff

Faculty of Biotechnology and Biomolecular Sciences, Universiti Putra Malaysia, 43400 Serdang, Selangor DE, Malaysia
IGS Intergenic sequences

RACE Rapid amplification of cDNA ends

ORF Open reading frame

\section{Introduction}

Newcastle disease (ND) is a fatal avian disease that affects most species of birds and currently remains as a constant major threat to commercial poultry production [1]. The severity of the infection varies with different species, and it has led to severe economic losses in the poultry industry worldwide. First detected in Java, Indonesia in 1926 and in Newcastle-on-Tyne, England in 1927 [2, 3], ND is now recognized as a highly contagious disease. The disease is caused by Newcastle disease virus (NDV) or avian paramyxovirus 1 which is a member of the genus Avulavirus of the family Paramyxoviridae [4]. It has various degrees of severity depending on the strain of virus and is classified into three pathotypes: the lentogenic strains are non-virulent, the mesogenic strains are intermediate virulent, and the velogenic (velogenic neurotropic or velogenic viscerotropic) strains are highly virulent and cause high mortality [5].

The genome of NDV contains a non-segmented singlestranded negative-sense RNA of approximately $15.2 \mathrm{~kb}$ [6-8]. Its structure is in the order of $3^{\prime}-5^{\prime}$ and contains six genes which encode the nucleocapsid (NP) protein, phosphoprotein $(\mathrm{P})$, matrix $(\mathrm{M})$ protein, fusion $(\mathrm{F})$ protein, hemagglutinin-neuraminidase $(\mathrm{HN})$ protein, and large (L) protein. During replication, two additional proteins known as $\mathrm{V}$ and $\mathrm{W}$ proteins $[9,10]$ are also produced by RNA editing during $P$ gene transcription. The anti-genomic RNA serves as a template for the synthesis of full-length 
genomic RNA [11]. The replication of NDV strictly follows "the rule of six" where efficient replication only takes place if the genome size is a multiple of six nucleotides (nt) [8]. The gene is flanked by a leader and a trailer sequence at its $3^{\prime}$ and $5^{\prime}$ ends, respectively [12]. Meanwhile, each gene contains an untranslated region (UTR) which is a conserved transcriptional control sequence at the beginning and end of the gene, known as the gene start and gene end, respectively $[13,14]$. UTR is known to play a role in viral genome transcription, translation, and virulence effect [15]. Located between the gene boundaries are non-coding intergenic sequences (IGS). The length within this region varies from 1 to $47 \mathrm{nt}[6,16]$.

Classification of NDV is commonly conducted by categorizing NDV into two major divisions, Class I and Class II. Class I consists of strains of genome size $15,198 \mathrm{bp}$, and Class II contains strains of genome size 15,186 and 15,192 bp. In addition, Class I comprises only avirulent strains of NDV [17]. Class II can be further divided into ten genotypes I to X [17-21]. The first panzootic in the 1920s was caused by genotypes II, III, and IV, and the second and third panzootics were caused by genotypes V-VI [22-24]. Genotype VII which is further subdivided into five subgenotypes (VII a-e) is responsible for the fourth panzootic which is currently on-going [18, 20, 25-28]. Finally, genotypes VIII, IX, and X have been found in South Africa, China, and Taiwan, respectively [18, 19, 21, 29]. The most recently proposed classification system of NDV genotypes was based on complete $\mathrm{F}$ gene sequences, and it revealed that Class I viruses contain a single genotype while Class II NDV isolates contain 15 genotypes [30].

AF2240 is a Malaysian viscerotropic velogenic strain that was isolated during an outbreak in the country in the 1960s [31]. There have been several in vivo and in vitro studies conducted on this strain on its oncolytic effect on brain tumor cells, MCF-7 breast cancer cells, HeLa cervical cancer cells and also on its cytolytic effects against leukemic cell lines [32-36]. Currently, it is used as the challenge virus in vaccine trials in Malaysia [37]. The sequences of six genes of this strain were submitted to NCBI from various authors over a period of time ranging from 1995 to 2005. HN gene was sequenced in 1995 [38], $\mathrm{M}$ and $\mathrm{F}$ gene in 1998, $\mathrm{P}$ and NP genes were sequenced in 2000, and L gene in 2003 (GenBank: AF060563, AY262106, AF048763, AF284647, AF284646, and $\mathrm{X} 79092)$. We decided to complete the remaining genome sequence of this strain (UTR, promoters, $3^{\prime}$ leader, and $5^{\prime}$ trailer) and re-amplify the genes for verification. However, due to the findings of some differences with the previously reported gene sequence of AF2240, we have renamed this strain as AF2240-I, a derivative of AF2240. We report here the complete genome sequence of this derivative and its relationship with other strains.

\section{Results and discussion}

Complete genome analysis

The amplification of $\mathrm{HN}$ gene of the strain given (initially presumed AF2240) has indicated the presence of Arg 403 residue in the $\mathrm{HN}$ gene, which was reported to be absent in the $\mathrm{HN}$ gene of strain AF2240 [38]. A frameshift was also observed between the amplified M gene of AF2240-I and the published sequence of AF2240. AF2240-I notes a distinguishable frameshift with a deletion of an adenosine at position 585 and an addition of thymine at position 933 of the ORF in the M gene. The frameshift may be due to the interference of quasispecies contributed by mutations that occur through errors made in the process of copying existing RNA genome sequences [39]. Previously recorded frameshifts were noted in the $\mathrm{L}$ gene of NDV strain Clone30, a vaccine strain derived from the lentogenic NDV strain La Sota [40]. With the exception of the HN and M gene differences noted in the sequencing results of AF2240, the remaining four genes were highly similar and differed by only $7 \mathrm{nt}$ at most, located in the ORFs of the genes. The dissimilarities in the $\mathrm{HN}$ and $\mathrm{M}$ gene had led to the decision for the strain to be renamed AF2240-I, and its complete genome sequence was deposited into GenBank [GenBank: JX012096]. The possibility of these differences may lie inthe numerous passaging history of the strain AF2240. The presence of Arg403 at the exact same position that it was reported missing [38] may also indicate a possibility that the strains were derived independently from a common progenitor.

The genome of AF2240-I is 15,192 nt in length, which follows the rule of six for a competent viral replication. The difference in genome lengths is contributed by the additional $6 \mathrm{nt}$ in the $3^{\prime}$ UTR of NP gene or $12 \mathrm{nt}$ in the ORF of P gene [22, 41]. AF2240-I contains the $6 \mathrm{nt}$ insertion confirming the genome length is $15,192 \mathrm{nt}$.

Whole genome comparison was performed on AF2240-I and 63 other NDV strains. Table 1 shows that strains QH1, QH4, Fontana, Largo, and Italien shared the highest identity of nt (>90\%) with strain AF2240-I, in contrast to the strains of Class I which showed the least nucleotide identity. QH1 and QH4 are of genotype VIII while Fontana, Largo, and Italien belong to genotypes VI, V, and IV, respectively.

As previously recorded, there were considerable variations observed in the non-coding regions of NP and P genes among virulent and non-virulent strains [6]. The velogenic strains containing $15,192 \mathrm{nt}$ genome length share $\geq 88 \%$ sequence homology at nt level. QH1 and QH4 are highly similar with $93 \%$ homology. Strains of $15,186 \mathrm{nt}$ genome lengths differ in nt identity based on the strain virulence. Italien and Herts/33 (genotype IV) show a similarity of 
Table 1 Comparison of whole genome sequence of various NDV strains with AF2240-I

\begin{tabular}{|c|c|c|c|c|c|c|}
\hline Strains & Years & Origin & Pathogenicity & Genotype & Accession no. & Genome similarity \\
\hline QH1 & 1979 & Western China & Velogenic & VIII & FJ751919 & 93 \\
\hline QH4 & 1985 & Western China & Velogenic & VIII & FJ751918 & 93 \\
\hline Fontana & 1972 & USA & Velogenic & VI & AY562988 & 92 \\
\hline Italien & 1944 & Italy & Velogenic & IV & EU293914 & 92 \\
\hline Largo & 1971 & USA & Velogenic & V & AY562990 & 92 \\
\hline Mexico P05 & 2005 & Mexico & Velogenic & V & HM117720 & 91 \\
\hline ZhJ-3 & 1997 & China & Velogenic & VI & FJ766529 & 91 \\
\hline Herts/33 & 1933 & UK & Velogenic & IV & AY74140 & 91 \\
\hline Sweden/95 & 1995 & Sweden & Velogenic & VI & HQ839733 & 90 \\
\hline Cockatoo & 1990 & Indonesia & Velogenic & VII & AY562985 & 90 \\
\hline NDV-2/chicken/Namakkal & 1987 & India & Velogenic & IV & GU187941 & 90 \\
\hline $\mathrm{XJ}-2 / 97$ & 1997 & China & Velogenic & VII & JN618348 & 89 \\
\hline Fujian/FP1 & 2002 & China & Velogenic & VII & FJ872531 & 89 \\
\hline Mukteswar & 2010 & China & Mesogenic & III & JF950509 & 89 \\
\hline Guangxi14 & 2002 & China & Velogenic & VII & JX193075 & 89 \\
\hline JS/07/16/Pi & 2007 & China & Velogenic & VI & FJ766527 & 89 \\
\hline NA-1 & $\mathrm{n} / \mathrm{a}$ & China & Velogenic & VII & DQ659677 & 89 \\
\hline Dove/Italy & 2000 & Italy & Velogenic & VI & AY562989 & 89 \\
\hline Sweden/97 & 1997 & Sweden & Velogenic & VII & GU585905 & 89 \\
\hline ZJ1 & 2000 & China & Velogenic & VII & AF431744 & 89 \\
\hline Pi/Rus/Vladimir/687 & 2005 & Russia & Velogenic & VI & JF827026 & 89 \\
\hline PX2/03 & 2003 & China & Velogenic & VII & JN653340 & 89 \\
\hline Guangxi7 & 2002 & China & Velogenic & VII & DQ485229 & 89 \\
\hline China/SDLC & 2011 & China & $\mathrm{n} / \mathrm{a}$ & VI & JQ979176 & 89 \\
\hline F48E9 & 1946 & China & Lentogenic & IX & FJ436302 & 89 \\
\hline Guangxi11 & 2003 & China & Velogenic & VII & DQ485231 & 89 \\
\hline GM & $\mathrm{n} / \mathrm{a}$ & China & Velogenic & VII & DQ486859 & 89 \\
\hline Rus/Kemerovo/0267 & 2009 & Russia & Velogenic & VI & JF827027 & 89 \\
\hline SRZ03 & 2003 & China & Velogenic & II & EU167540 & 88 \\
\hline 2K3 Chennai & 2000 & India & Velogenic & IV & FJ986192 & 88 \\
\hline Ulster/67 & 1967 & UK & Lentogenic & I & M24694 & 88 \\
\hline YZCQ/Liaoning & 2008 & China & Velogenic & VII & JX867334 & 88 \\
\hline Go/CH/HLJ/LL01 & 2008 & China & Velogenic & VII & GU143550 & 88 \\
\hline Egret/China/Guangxi & 2011 & China & Velogenic & VII & JX193074 & 88 \\
\hline Banjarmasin & 2011 & Indonesia & Velogenic & VII & HQ697254 & 88 \\
\hline Sukorejo & 2011 & Indonesia & Velogenic & VII & HQ697255 & 88 \\
\hline V4 & 1966 & Australia & Lentogenic & I & JX524203 & 88 \\
\hline NDV4-C & 1996 & China & Lentogenic & I & JX443519 & 88 \\
\hline TS09-C & 2009 & China & $\mathrm{n} / \mathrm{a}$ & I & JX110635 & 88 \\
\hline Peru/1918-03 & 2008 & Peru & Velogenic & VII & JN800306 & 88 \\
\hline China/SD04 & 2011 & China & Velogenic & VII & JQ015296 & 88 \\
\hline China/SDWF07 & 2011 & China & $\mathrm{n} / \mathrm{a}$ & VII & JQ015295 & 88 \\
\hline Togo/ako & 2009 & Togo & Velogenic & VII & JX390609 & 88 \\
\hline CP/Pakistan & 2010 & Pakistan & Velogenic & VII & JN682211 & 88 \\
\hline MM19 & 2012 & Pakistan & Velogenic & VII & JX532092 & 87 \\
\hline WDK/JX/7793 & 2004 & China & Lentogenic & I & HM125898 & 87 \\
\hline M4 & 2007 & China & $\mathrm{n} / \mathrm{a}$ & I & JN653339 & 87 \\
\hline Dominican Rep. & 2008 & Dominican Rep. & Velogenic & $\mathrm{n} / \mathrm{a}$ & JX119193 & 87 \\
\hline
\end{tabular}


Table 1 continued

\begin{tabular}{lllllll}
\hline Strains & Years & Origin & Pathogenicity & Genotype & Accession no. & Genome similarity \\
\hline CBU2374 & 2007 & South Korea & n/a & I & JX401405 & 87 \\
Guangxi16 & 2008 & China & Lentogenic & I & JX193077 & 87 \\
D3 & 2007 & China & Lentogenic & I & HM063422 & 87 \\
BHG/Sweden & 1994 & Sweden & Lentogenic & I & GQ918280 & 86 \\
Egypt/1 & 2005 & Egypt & Velogenic & II & FJ939313 & 86 \\
NDV2K17/Quail/Chennai & 1998 & India & Velogenic & II & HQ902590 & 86 \\
HX01 & 2009 & China & Lentogenic & II & JF795531 & 86 \\
Clone30 & n/a & USA & Lentogenic & II & Y18898 & 86 \\
La Sota & 1946 & USA & Lentogenic & II & JF950510 & 86 \\
B1 & 1947 & USA & Lentogenic & II & AF077761 & 86 \\
Guangxi21 & 2010 & China & Lentogenic & II & JX193082 & 86 \\
Teal/France & 2010 & France & Lentogenic & Class I & JQ013039 & 72 \\
DE-R49 & 1949 & Germany & Lentogenic & Class I & DQ097393 & 72 \\
D-AH-10-02 & 2010 & China & Lentogenic & Class I & JN688863 & 72 \\
Ch-Zj1 & 1986 & China & Lentogenic & Class I & JN688863 & 72 \\
\hline
\end{tabular}

Genome similarity of the nucleotides is shown in percentage. QH1, QH4, Fontana, and Italien show the highest percentage of nucleotide identity (based on pairwise distances calculated using Mega5)

Table 2 Total gene, coding and protein length of NDV strain AF2240-I

\begin{tabular}{|c|c|c|c|c|c|c|c|c|}
\hline Gene/region & Leader & NP & $\mathrm{P}$ & M & $\mathrm{F}$ & HN & $\mathrm{L}$ & Trailer \\
\hline Length (nt) & 55 & 1,753 & 1,451 & 1,241 & 1,792 & 2,002 & 6,703 & 114 \\
\hline ORF (nt) & - & 1,470 & 1,188 & 1,095 & 1,662 & 1,749 & 6,615 & - \\
\hline Protein length (nt) & - & 489 & 395 & 364 & 553 & 582 & 2,204 & - \\
\hline Intergenic (nt) & - & 1 & 1 & 1 & 31 & 47 & - & - \\
\hline \multicolumn{9}{|c|}{ Nucleotide/amino acid identity $(\%)^{\mathrm{a}}$} \\
\hline QH1 & 97 & 97 & 91 & 95 & 97 & 95 & 96 & 91 \\
\hline QH4 & 97 & 97 & 92 & 95 & 97 & 95 & 96 & 91 \\
\hline Fontana & 91 & 98 & 92 & 98 & 96 & 95 & 96 & 87 \\
\hline Largo & 93 & 97 & 89 & 98 & 95 & 94 & 96 & 86 \\
\hline Italien & 92 & 97 & 90 & 97 & 95 & 86 & 96 & 87 \\
\hline
\end{tabular}

Intergenic sequences are also provided. The five highest strains of nucleotide or protein similarities are shown

${ }^{a}$ Percentage of similarity for leader and trailer was based on nucleotide similarity, and the percentage of similarity for NP, P, M, F, HN, and L proteins was based on amino acid

$91 \%$; meanwhile, Clone 30, La Sota, and B1 (genotype II) are only $86 \%$ similar. Strains of Class I showed a similarity of $72 \%$.

Similar to other paramyxoviruses, AF2240-I consists of six genes encoding six proteins (Table 2). The start which is the ribosomal binding site of NP, P, M, F, and $\mathrm{HN}$ genes was found to be ACGGGTAGAA, and for L, it was found to be ACGGGTAGGA. The gene terminal was TTAGA $6 / 7$ for NP, M, and L genes, whereas it was $\mathrm{TAAGA}_{6}$ for P, F, and $\mathrm{HN}$ genes.

The $3^{\prime}$-leader and 5'-trailer regions of AF2240-I consist of $55 \mathrm{nt}$ and $114 \mathrm{nt}$, respectively (Table 2). The $55 \mathrm{nt}$ of the leader sequence was shown to be close to $\mathrm{QH} 1$ and $\mathrm{QH} 4$ with an identity of $97 \%$ followed by strain Mexico P05 (genotype V) at $94 \%$. The leader sequence of strain AF2240-I also showed complete similarity to the first $12 \mathrm{nt}$ of 62 strains except strains CP/Pakistan and Namakkal/ Tamil. Meanwhile, the trailer sequence of AF2240-I shows a highly conserved region of $20 \mathrm{nt}$ at the $5^{\prime}$ region with most strains. (Figure not included). The highly conserved region of the trailer among most strains of varied virulence may not play a role in NDV virulence [6].

The first three IGSs of AF2240-I, the NP-P, P-M, and $\mathrm{M}-\mathrm{F}$ gene junctions each had only $1 \mathrm{nt}$. The remaining two IGSs, F-HN and HN-L, contain 31 and 47 nt. There were studies on the unsuccessful attempts to recover viable NDV 
through replacing the IGS at the F-HN and HN-L gene junctions. Moreover, changes in the number of nt within these IGS seemed to affect the transcription of the downstream genes and viral pathogenicity [12].

When compared with Class I strains, AF2240-I displayed frameshift mutations in the trailer region, HN-L IGS region, and in all genes except for $\mathrm{HN}$. These insertions and deletions (indels) are also noticed in all other Class II strains at the same nt position. Within the NP gene, indels are noticed at nt positions 1,596, 1,618, 1,681, 1,759, and 1,785 comprising $2 \mathrm{nt}$ insertion, $1 \mathrm{nt}$ deletion, $1 \mathrm{nt}$ insertion, $1 \mathrm{nt}$ insertion, and $3 \mathrm{nt}$ deletion, respectively, compared to those of Class I strains. The highest occurrences of indels are observed in the $\mathrm{P}$ gene. Meanwhile, the $\mathrm{F}$ gene recorded only two indels; an insertion of adenosine and a deletion of thymine at nucleotide positions 1,718 and 1,748 , respectively. These indels may cause low nucleotide similarity between AF2240-I and Class I strains, and this observation may clarify the relationship between Class I and Class II NDVs.

\section{Protein analysis}

The complete nucleotide sequence of the NP gene of strain AF2240-I contains 1,753 nt with an open reading frame (ORF) of 1,470. This ORF contains a coding region of 489 amino acid [42] residues. Comparison of the NP protein with those from selected strains of NDV shows that the NP gene is quite conserved among all strains with a conservation value of more than $90 \%$ (Table 3 ). Fontana and QH1 displayed the highest amino acid similarity of $98 \%$, while QH4 came second at $97 \%$. As previously reported, the conservation of amino acids is observed to be high in the first 400 aa and becomes more divergent from 401 aa till the end of the gene [6]. Two unique substitutions of Asn 80 with His and Thr 100 with Ala were recorded in the NP protein of AF2240-I.

The $\mathrm{P}$ gene has a length of $1,451 \mathrm{nt}$ with an ORF of $1,188 \mathrm{nt}$, and it is edited at the editing site (476-CUAAAAAGGGCCCA-489) to be transcribed into three proteins, $\mathrm{P}, \mathrm{V}$, and $\mathrm{W}[9,10]$. Just as observed in the $\mathrm{P}$ gene, there is least variability between Fontana, QH1, QH4, and AF2240-I with a difference below $10 \%$. Meanwhile, strains of Class I show a similarity of only 27 $\%$ indicating a high divergence of the $\mathrm{P}$ gene between AF2240-I and Class I strains mainly contributed by the additional $12 \mathrm{nt}$ which are present in all Class I strains. The $M$ protein is involved in the assembly of NDV [37]. AF2240-I translates the ORF of M gene into 364 aa. This frameshift of AF2240-I from its derivative AF2240 has further increased the homology of amino acid of AF2240-I when compared with 63 other strains. The identity value of amino acid was at an average of $94 \%$; the lowest being strain Mexico P05 (genotype V) and the highest being strain Fontana (genotype VI). Strains of Class I recorded an identity value of $91 \%$.

The pathogenicity of NDV strains is mainly determined by the F protein cleavage site [43]. The F gene of 1,792 nt translates the ORF into 1,662 aa. The cleavage site of AF2240-I is 112-R-R-Q-K-R-F-117 which corresponds to those of other virulent strains [41, 44]. In general, when compared with selected strains, the F protein of AF2240-I shows a high conservation value from 85 to $97 \%$. All strains of Class II show a conservation value of above $90 \%$ of amino acids. There is a high divergence observed at the beginning of the sequence from 2 to 32 aa. There is only one unique substitution of Thr 367 with Ala of AF2240-I.

The HN protein is reported to be responsible for virushost cell interaction $[14,45]$. There have also been reports on the role of $\mathrm{HN}$ in virulence determination [46]. A variation in the size of the HN gene of NDV strains has also been reported due to the position of the stop codon resulting in amino acid lengths of 571, 577, 578, 580, 585, and 616 aa [47, 48]. In this paper, we report that the complete nucleotide sequence of the HN gene of the strain AF2240-I is 2,002 nt long with an ORF of 1,749 nt encoding 582 aa.

It has been shown that the length of $\mathrm{HN}$ protein differs regardless of strain virulence [22, 47]; meanwhile, genotypes have shown some form of relationship in terms of HN length [49]. Although most strains of genotype VIII possess an HN length of 571 aa, our result shows that the HN of AF2240-I is made up of 582 aa. This is the first report of such length. This indicates that $\mathrm{HN}$ protein length varies in spite of coming from the same genotype. Irrespective of different lengths of the $\mathrm{HN}$ protein, the identity recorded is still considerably high with strain Fontana at 95 $\%$ as compared to that of AF2240-I. In this comparison, five amino acids; Val 50, Phe 56, Val 117, Leu 175, and Met 378 of AF2240-I recorded unique substitutions. The highly conserved amino acid regions that are involved in the activity of sialic acid-binding Arg 174, Tyr 526, Glu 401, and Arg 416 [50] in the HN protein are also present in AF2240-I. L is the largest structural protein of NDV comprising 2,204 aa that are involved in the synthesis of viral RNA [51]. This protein of AF2240-I shows a high conservation value at $96 \%$ with QH4, QH1, Italien, and Fontana. Although it has been reported that the $\mathrm{L}$ gene was the most conserved among other genes, in our current study, NP gene showed the highest percentage of amino acid homology [49].

Phylogenetic analysis

Based on the classification system of two major divisions, Class I and Class II [22, 52, 53], it was shown that the F 
Table 3 Estimates of evolutionary divergence of each gene between strain AF2240-I and selected strains

\begin{tabular}{|c|c|c|c|c|c|c|}
\hline \multirow[t]{2}{*}{ Strains } & \multicolumn{6}{|c|}{ Distance } \\
\hline & NP & $\mathrm{P}$ & M & $\mathrm{F}$ & $\mathrm{HN}$ & $\mathrm{L}$ \\
\hline B1 & 92.64 & 83.80 & 89.84 & 90.24 & 89.58 & 74.11 \\
\hline Banjarmasin & 96.52 & 84.56 & 95.33 & 95.30 & 92.12 & 78.53 \\
\hline BHG/Sweden & 93.46 & 84.81 & 93.68 & 91.86 & 90.52 & 73.91 \\
\hline CBU2374 & 94.48 & 86.08 & 93.68 & 93.49 & 91.72 & 73.54 \\
\hline 2K3 Chennai & 95.91 & 87.34 & 91.21 & 91.86 & 89.49 & 77.89 \\
\hline Sweden/95 & 96.32 & 89.37 & 97.25 & 96.02 & 94.57 & 80.84 \\
\hline China/SDLC & 95.09 & 86.58 & 95.88 & 94.21 & 91.77 & 79.50 \\
\hline China/SDWF07 & 96.11 & 85.82 & 94.23 & 93.49 & 91.77 & 77.08 \\
\hline Ch-Zj1 & 91.41 & 27.00 & 90.66 & 84.99 & 81.72 & 48.52 \\
\hline Clone30 & 93.05 & 86.08 & 90.38 & 90.96 & 89.76 & 73.91 \\
\hline Cockatoo & 94.68 & 88.10 & 95.88 & 96.02 & 92.99 & 80.78 \\
\hline CP/Pakistan & 94.68 & 84.56 & 96.15 & 94.58 & 92.12 & 77.67 \\
\hline D3 & 94.27 & 86.84 & 93.13 & 93.49 & 90.97 & 73.32 \\
\hline D-AH-10-02 & 90.80 & 27.00 & 90.66 & 84.09 & 81.90 & 48.47 \\
\hline DE-R49 & 90.80 & 27.00 & 90.93 & 86.80 & 83.62 & 48.85 \\
\hline Dominican Rep. & 95.09 & 86.84 & 95.33 & 91.50 & 91.24 & 74.83 \\
\hline Dove/Italy & 94.07 & 86.33 & 93.41 & 95.12 & 92.36 & 80.35 \\
\hline Egret/China/Guangxi & 96.52 & 86.08 & 95.60 & 93.85 & 93.17 & 77.78 \\
\hline Egypt/1 & 93.46 & 86.08 & 91.48 & 91.32 & 88.54 & 74.50 \\
\hline F48E9 & 95.71 & 86.33 & 92.03 & 93.85 & 91.42 & 79.01 \\
\hline Fontana & 97.96 & 92.15 & 97.80 & 96.38 & 95.45 & 84.49 \\
\hline Fujian/FP1 & 96.11 & 87.34 & 95.88 & 93.85 & 93.70 & 79.60 \\
\hline GM & 97.14 & 87.59 & 95.60 & 93.31 & 93.35 & 78.85 \\
\hline Go/CH/HLJ/LL01 & 95.71 & 86.58 & 95.33 & 93.31 & 93.35 & 77.40 \\
\hline Guangxi7 & 95.71 & 87.34 & 94.78 & 93.31 & 93.35 & 79.07 \\
\hline Guangxi11 & 96.73 & 86.84 & 94.78 & 93.67 & 92.64 & 78.53 \\
\hline Guangxi14 & 96.52 & 87.85 & 95.88 & 93.85 & 93.17 & 78.80 \\
\hline Guangxi16 & 93.87 & 85.82 & 93.96 & 92.41 & 91.03 & 73.70 \\
\hline Guangxi21 & 92.84 & 86.08 & 90.38 & 90.96 & 89.24 & 73.75 \\
\hline Herts/33 & 96.73 & 90.63 & 95.60 & 95.30 & 92.47 & 82.34 \\
\hline HX01 & 93.05 & 86.33 & 90.11 & 90.78 & 89.06 & 74.02 \\
\hline Italien & 97.14 & 90.63 & 95.88 & 95.12 & 92.99 & 82.98 \\
\hline $\mathrm{JS} / 07 / 16 / \mathrm{Pi}$ & 94.89 & 86.84 & 95.88 & 94.94 & 92.99 & 80.09 \\
\hline Rus/Kemerovo/0267 & 95.50 & 85.32 & 95.88 & 92.59 & 92.29 & 78.37 \\
\hline Largo & 97.14 & 88.86 & 97.53 & 94.58 & 94.05 & 85.78 \\
\hline La Sota & 91.82 & 86.33 & 90.11 & 90.78 & 89.76 & 73.79 \\
\hline M4 & 95.09 & 84.56 & 94.23 & 93.67 & 91.21 & 73.81 \\
\hline Mexico P05 & 96.52 & 86.84 & 85.99 & 96.02 & 93.87 & 83.79 \\
\hline MM19 & 94.89 & 84.56 & 86.81 & 93.31 & 88.79 & 77.28 \\
\hline Mukteswar & 94.68 & 86.08 & 92.31 & 93.13 & 91.42 & 80.62 \\
\hline NA-1 & 95.91 & 87.34 & 95.88 & 94.76 & 93.17 & 78.96 \\
\hline NDV-2/chicken/Namakkal & 95.71 & 87.34 & 92.03 & 92.22 & 88.79 & 82.98 \\
\hline NDV2K17/Quail/Chennai & 92.64 & 86.33 & 91.21 & 91.50 & 88.19 & 74.13 \\
\hline NDV4-C & 94.89 & 86.08 & 94.23 & 93.13 & 91.21 & 76.70 \\
\hline Peru/1918-03 & 95.91 & 84.81 & 95.33 & 93.85 & 91.24 & 77.67 \\
\hline Pi/Rus/Vladimir/687 & 96.52 & 85.57 & 95.05 & 93.85 & 92.29 & 79.07 \\
\hline $\mathrm{PX} 2 / 03$ & 96.11 & 87.09 & 95.60 & 93.84 & 93.35 & 78.90 \\
\hline
\end{tabular}


Table 3 continued

\begin{tabular}{|c|c|c|c|c|c|c|}
\hline \multirow[t]{2}{*}{ Strains } & \multicolumn{6}{|c|}{ Distance } \\
\hline & NP & $\mathrm{P}$ & M & $\mathrm{F}$ & $\mathrm{HN}$ & $\mathrm{L}$ \\
\hline QH1 & 97.55 & 91.39 & 95.60 & 97.29 & 95.27 & 86.53 \\
\hline QH4 & 97.34 & 91.90 & 95.60 & 96.93 & 94.75 & 86.63 \\
\hline China/SD04 & 96.11 & 86.33 & 94.78 & 93.49 & 92.29 & 77.19 \\
\hline SRZ03 & 97.14 & 86.84 & 95.60 & 91.68 & 93.17 & 78.31 \\
\hline Sukorejo & 96.93 & 86.33 & 95.88 & 95.48 & 91.77 & 77.40 \\
\hline Sweden/97 & 96.11 & 86.58 & 96.70 & 94.58 & 92.64 & 80.03 \\
\hline Teal/France & 91.21 & 26.00 & 92.31 & 87.52 & 84.28 & 48.95 \\
\hline Togo/ako & 94.27 & 87.85 & 95.05 & 93.49 & 92.12 & 76.69 \\
\hline TS09-C & 94.89 & 86.08 & 93.96 & 92.95 & 90.86 & 76.70 \\
\hline Ulster/67 & 94.68 & 86.08 & 91.48 & 92.59 & 91.55 & 77.08 \\
\hline V4 & 94.89 & 86.08 & 94.23 & 93.13 & 91.38 & 76.76 \\
\hline WDK/JX/7793 & 95.30 & 86.08 & 94.51 & 93.67 & 91.90 & 73.81 \\
\hline $\mathrm{XJ}-2 / 97$ & 96.93 & 86.84 & 96.15 & 94.94 & 94.22 & 79.96 \\
\hline YZCQ/Liaoning & 96.52 & 84.30 & 95.05 & 93.67 & 93.35 & 77.78 \\
\hline ZhJ-3 & 97.34 & 91.14 & 97.80 & 96.20 & 95.45 & 82.02 \\
\hline ZJ1 & 96.52 & 86.84 & 95.60 & 93.31 & 93.35 & 78.96 \\
\hline
\end{tabular}

The number of amino acid differences per site between AF2240-I and 63 strains in all six gene sequences is shown. All positions containing gaps and missing data were eliminated. Evolutionary analyses were conducted in MEGA5

gene of strain AF2240 belongs to genotype VIII of class II [28]. Meanwhile, under the new unified classification of NDV genotypes of F gene [30], AF2240 is still classified as genotype VIII. Using the previous classification method based on two major divisions, a phylogenetic tree of the $\mathrm{F}$ gene and full length of AF2240-I show similar result to that of AF2240 and suggest a phylogenetic clustering with strains QH1 and QH4 (genotype VIII). The sequence homology among the two isolates of genotype VIII, QH1 and QH4, was $93 \%$ (Fig. 1).

The high degree of nucleotide identity identified with certain velogenic strains would serve as a reference for future studies on AF2240-I. Availability of the complete genome sequence of strain AF2240-I for the first time in Malaysia is crucial in engineering its full length virus for various applications. The most profound application of genetically engineered virus is for vaccine development and as a therapeutic agent.

\section{Methods and materials}

\section{Preparation of virus and RT-PCR}

Newcastle disease virus strain AF2240 was available from virus stock at Faculty of Biotechnology and Biomolecular Sciences, Universiti Putra Malaysia. It was grown in 9-dayold embryonated SPF chicken eggs and purified as previously described [54]. Viral genomic RNA was isolated with Trizol reagent (Invitrogen, USA). The cDNA for UTR region was made with RevertAid Premium first strand cDNA synthesis kit (Thermo, USA) using gene-specific primers.

Amplification of the untranslated regions

PCR primer sets were designed from the available sequences of strain AF2240 [GenBank: AF060563, AY262106, AF048763, AF284647, AF284646, and X79092]. Primers used to amplify all UTRs are as follows: primers 5'-GCAC AGAGCACCACCCACCC- $3^{\prime}$ and $5^{\prime}$-TCGGGGTTGTCCT GGCTGGT-3' for NP-P, primers $5^{\prime}$-GCGGGCGGACCTG ATATGGG- $3^{\prime}$ and $5^{\prime}$-GCTGCTGGAGGGAAGGGCAG-3' for P-M, primers 5'-AGGCACCCAACGTGCTGTCG-3' and $5^{\prime}$-CTGCAAGTGGCCTGCCGTCT- $3^{\prime}$ for M-F, primers 5'-TCCGGTGTAGTTAGCCTGGT-3' and 5'-ACGGA GACTCAAGGGCCACC- $3^{\prime}$ for F-HN, and primers $5^{\prime}$-AA GGCAGCATACACGACATCGACA-3' and 5'-TGGAGC GGCCGACTCAAGTA-3'. All PCR products were amplified using Platinum Pfx polymerase (Invitrogen, USA) followed by gel purification with QIAquick Gel Extraction Kit (Qiagen, USA) and cloned into pJET 1.2/blunt cloning vector using CloneJET PCR Cloning Kit (Thermo, USA). Several independent clones were sequenced from both directions to verify the plasmid insertion. 


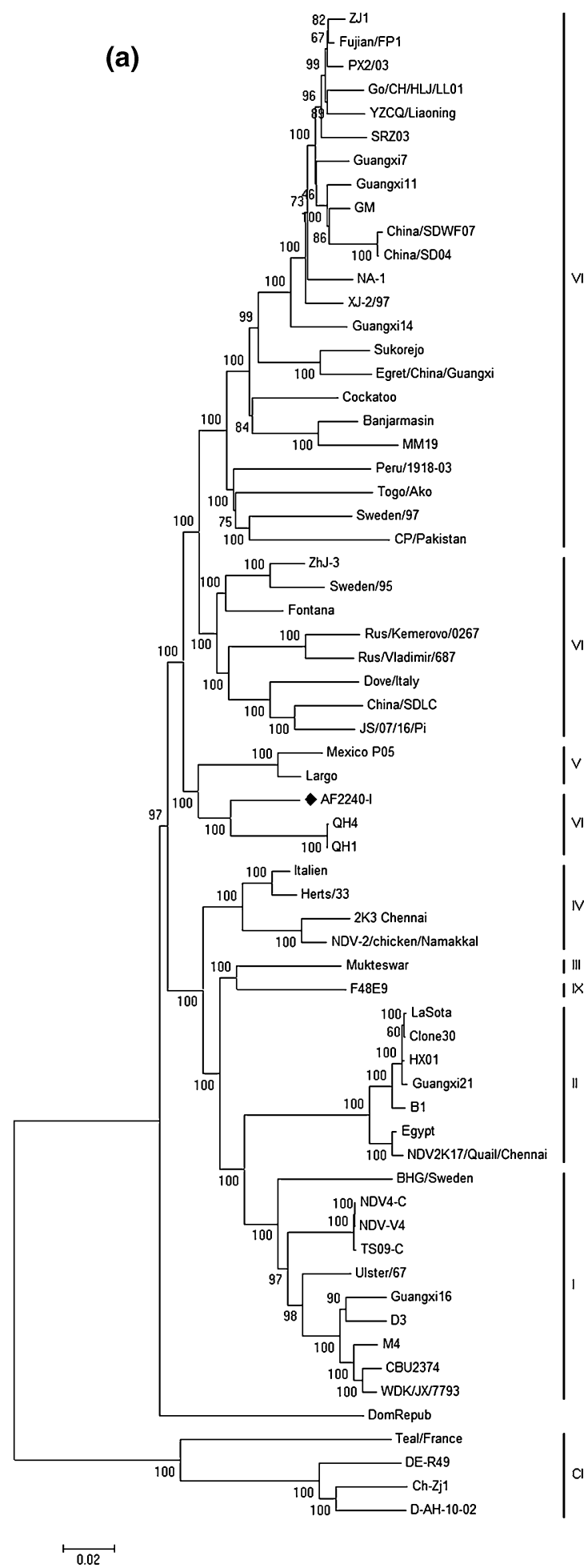

Fig. 1 The phylogenetic tree inferred using the neighbor-joining method. a Phylogenetic tree of the full length sequence. b Phylogenetic tree of the complete open reading frame of the $\mathrm{F}$ gene. The bootstrap consensus tree inferred from 1,000 replicates. Branches corresponding to partitions reproduced in $<50 \%$ bootstrap replicates are collapsed. The $\%$ of replicate trees in which the associated taxa clustered together in the bootstrap test $(1,000$ replicates $)$ is shown (b)

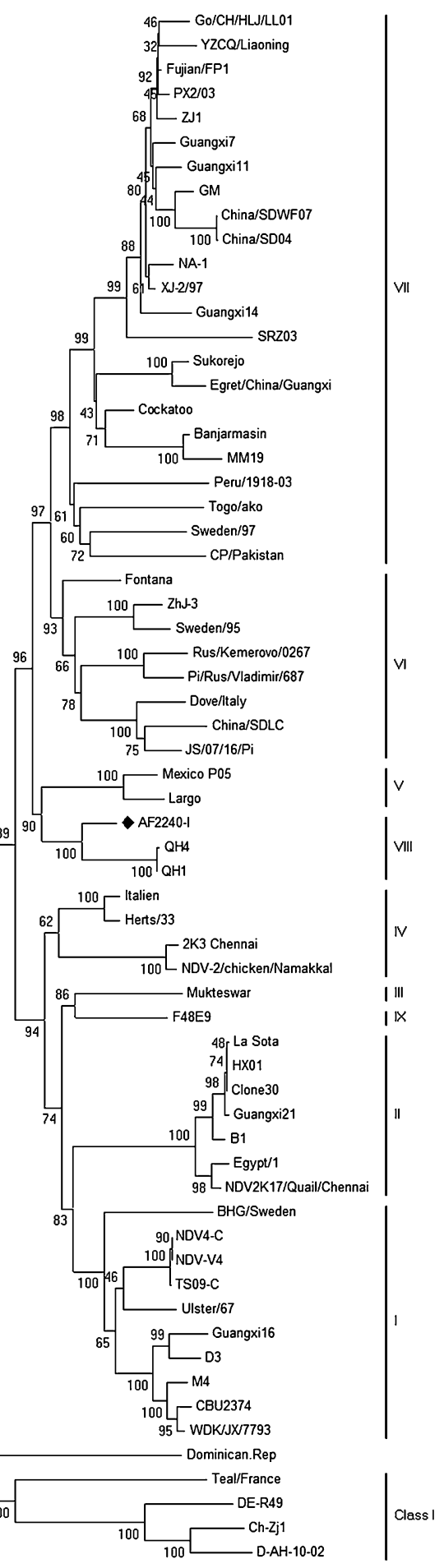

$\stackrel{\longmapsto}{\longmapsto .02}$

next to the branches. The tree is drawn to scale, with branch lengths in the same units as those of the evolutionary distances used to infer the phylogenetic tree. The evolutionary distances were computed using the p-distance method and are in the units of the number of base differences per site. Evolutionary analyses were conducted in MEGA5. Both trees indicate AF2240-I is from genotype VIII 
Amplification of the $3^{\prime}$ - and $5^{\prime}$-terminal ends of the viral RNA

The leader and trailer sequences at the $3^{\prime}$ - and $5^{\prime}$-terminal ends of the viral RNA, respectively, were determined by rapid amplification of cDNA ends (RACE) as described previously [8]. To determine the sequence of the $5^{\prime}$ end, primer L-cDNA (5'-GGTGATGTAATTGGCTTAGTAC TC- $3^{\prime}$ ), which was derived from the published sequence of the L-gene of NDV strain AF2240, was used to generate single-stranded cDNA with reverse transcriptase (RT) as described above. The single-stranded cDNA was ligated to anchor-primer anchor as previously published in a study on strain La Sota [8] using T4 RNA ligase [55]. One microliter of the ligation mixture was used in a PCR with Phusion Hot Start High-Fidelity DNA Polymerase (Thermo, USA) and primers used were anchor-comp (5'-GAAGGATCCAGAA TCGATAG-3'), complementary to anchor primer), and L-PCR (5'-CAGCCAAGGGATATTACAGTAACT-3'). The PCR consisted of 35 cycles of $1 \mathrm{~min}$ at $98{ }^{\circ} \mathrm{C}, 30 \mathrm{~s}$ at $55^{\circ} \mathrm{C}$, and $20 \mathrm{~s}$ at $72^{\circ} \mathrm{C}$. The PCR products were cloned into pJET 1.2 blunt/cloning. Three independent clones were sequenced from both directions. To determine the sequence of the $3^{\prime}$-terminal end, primer anchor was ligated to the $3^{\prime}$ end of genomic RNA with T4 RNA ligase as described by [56]. The mixture was incubated overnight at room temperature, and $5 \mu \mathrm{l}$ of the ligation reaction was used as template in a reverse transcription reaction with anchor-comp primer. One microliter of the $\mathrm{RT}$ reaction was used in a PCR reaction with primers anchor-comp and NP-PCR (5'-GGAGCTGCTCGT ATTCATC- $\left.3^{\prime}\right)$. The latter primer was derived from the published sequence of the NP gene of AF2240 strain. The RT-PCR and cloning conditions were as described above for the $5^{\prime}$ RACE. Three independent clones were sequenced from both directions. The genome was then sequenced at different positions to be crosschecked with the published sequence of AF2240.

Amplification of the genes

PCR primer sets for each gene were designed from the sequenced UTRs. All PCR products were amplified using Platinum $P f x$ polymerase (Invitrogen, USA) followed by gel purification with QIAquick Gel Extraction Kit (Qiagen, USA) and cloned into pJET 1.2/blunt cloning vector using CloneJET PCR Cloning Kit (Thermo, USA). Several independent clones were sequenced from both directions to verify the plasmid insertion.

Sequence analysis

All alignment and phylogenetic analyses were performed with MEGA5 software (Molecular Evolutionary Genetics
Analysis, version 5.0) by neighbor-joining method at 1,000 bootstrap values.

Acknowledgments KM was supported by a Graduate Research Fellowship, UPM. The study was supported by funds from HICOE Grant No: 6369101, Minister of Higher Education, Government of Malaysia.

Conflict of interests The authors declare that they have no competing interests.

\section{References}

1. D.J. Alexander, I. Capua, D.J. Alexander (eds.), Avian influenza and newcastle disease: a field and laboratory manual (Springer, Milan, 2009)

2. T.M. Doyle, J. Comp. Pathol. 40, 144 (1927)

3. F.C. Kraneveld, Nederlands-Indische Bladen voor Diergeneeskunde 38, 448 (1926)

4. M.A. Mayo, Arch. Virol. 147, 1655 (2002)

5. S. Krishnamurthy, Z. Huang, S.K. Samal, Virology 278, 168 (2000)

6. S. Krishnamurthy, S.K. Samal, J. Gen. Virol. 79, 2419 (1998)

7. R.J. Phillips, A.C.R. Samson, P.T. Emmerson, Arch. Virol. 143, 1993 (1998)

8. O. de Leeuw, B. Peeters, J. Gen. Virol. 80(Pt 1), 131 (1999)

9. N.S. Millar, P. Chambers, P.T. Emmerson, J. Gen. Virol. 69 (Pt 3), 613 (1988)

10. M. Steward, I.B. Vipond, N.S. Millar, P.T. Emmerson, J. Gen. Virol. 74(Pt 12), 2539 (1993)

11. B.S. Seal, D.J. King, D.P. Locke, D.A. Senne, M.W. Jackwood, J. Clin. Microbiol. 36, 1141 (1998)

12. Y. Yan, S.K. Samal, J. Virol. 82, 1323 (2007)

13. M.S. Galinski, S.L. Wechsler, in The Paramyxoviruses, ed. by D.W. Kingsbury (Plenum Press, New York, 1991), pp. 41-72

14. R.A. Lamb, D. Kolakofsky, in Fields Virology, ed. by B.N. Fields, D.M. Knipe, P.M. Howley (Lippincott-Raven, New York, 1996), pp. 1177-1204

15. Y. Yan, S.N. Rout, S.H. Kim, S.K. Samal, J. Virol. 83, 5943 (2009)

16. P. Chambers, N.S. Millar, R.W. Bingham, P.T. Emmerson, J. Gen. Virol. 67(Pt 3), 475 (1986)

17. A. Ballagi-Pordány, E. Wehmann, J. Herczeg, S. Belák, B. Lomniczi, Arch. Virol. 141, 243 (1996)

18. J. Herczeg et al., Arch. Virol. 144, 2087 (1999)

19. X.F. Liu, H.Q. Wan, X.X. Ni, Y.T. Wu, W.B. Liu, Arch. Virol. 148, 1387 (2003)

20. B. Lomniczi et al., Arch. Virol. 143, 49 (1998)

21. H.J. Tsai et al., Vet. Microbiol. 104, 19 (2004)

22. A. Czeglédi et al., Virus Res. 120, 36 (2006)

23. J. Herczeg et al., Avian Pathol. 30, 163 (2001)

24. E. Wehmann et al., Vet. Microbiol. 94, 269 (2003)

25. R. Liang et al., Vet. Microbiol. 87, 193 (2002)

26. Y.Y. Lien et al., Vet. Microbiol. 123, 194 (2007)

27. H. Liu et al., J. Virol. Methods 140, 206 (2007)

28. L. Yu, Z. Wang, Y. Jiang, L. Chang, J. Kwang, J. Clin. Microbiol. 39, 3512 (2001)

29. C. Abolnik et al., Arch. Virol. 149, 603 (2004)

30. D.G. Diel et al., Infect. Genet. Evol. 12, 1770 (2012)

31. M. Lai, A. Ibrahim, in Newcastle disease poultry: a new food pellet vaccine, ed. by J.W. Copland (ACIAR, Canberra, 1987), pp. $12-18$

32. F. Othman, A. Ideris, G. Motalleb, Z. Eshak, A. Rahmat, Yakteh Med. J. 12, 17 (2009) 
33. R. Ali et al., Neurochem. Res. 36, 2051 (2011)

34. A. Molouki et al., Virol. J. 8, 385 (2011)

35. A. Molouki, Y.T. Hsu, F. Jahanshiri, R. Rosli, K. Yusoff, Intervirology 53, 87 (2010)

36. A.M. Alabsi et al., Int. J. Mol. Sci. 12, 8645 (2011)

37. K. Yusoff, W.S. Tan, Avian Pathol. 30, 439 (2001)

38. W.S. Tan, C.H. Lau, B.K. Ng, A.L. Ibrahim, K. Yusoff, DNA Seq. 6, 47 (1995)

39. Y. Yu et al., Virol. J. 9, 120 (2012)

40. A. Romer-Oberdorfer, E. Mundt, T. Mebatsion, U.J. Buchholz, T.C. Mettenleiter, J. Gen. Virol. 80(Pt 11), 2987 (1999)

41. A. Paldurai, S. Kumar, B. Nayak, S.K. Samal, Virus Genes 41, 67 (2010)

42. T. Nakaya et al., J. Virol. 75, 11868 (2001)

43. B.P. Peeters, O.S. de Leeuw, G. Koch, A.L. Gielkens, J. Virol. 73, 5001 (1999)

44. E.W. Aldous, D.J. Alexander, Avian Pathol. 30, 117 (2001)

45. R. Deng et al., Virology 253, 43 (1999)
46. O.S. de Leeuw, G. Koch, L. Hartog, N. Ravenshorst, B.P. Peeters, J. Gen. Virol. 86, 1759 (2005)

47. T. Sakaguchi et al., Virology 169, 260 (1989)

48. A.R. Gould et al., Avian Pathol. 32, 361 (2003)

49. D. Wei et al., Virus Res. 135, 312 (2008)

50. H. Connaris et al., J. Virol. 76, 1816 (2002)

51. M. Hamaguchi, T. Yoshida, K. Nishikawa, H. Naruse, Y. Nagai, Virology 128, 105 (1983)

52. P.J. Miller, E.L. Decanini, C.L. Afonso, Infection. Genet. Evol. 10, 26 (2010)

53. B.S. Seal, D.J. King, J.D. Bennett, J. Clin. Microbiol. 33, 2624 (1995)

54. P. Ramanujam, W.S. Tan, S. Nathan, K. Yusoff, Arch. Virol. 147, 981 (2002)

55. D.C. Tessier, R. Brousseau, T. Vernet, Annu. Rev. Biochem. 158, 171 (1986)

56. H. Schutze et al., J. Gen. Virol. 76, 2519 (1995) 